\title{
Device Closure in Congenital Heart Disease
}

\section{Dr. Shyam Regmi*}

\section{Introduction}

A device to plug holes in the heart without open-heart surgery has been available for a decade. James Lock, M.D., chief cardiologist at Children's Hospital Boston, developed his clamshell occluder for that purpose and also developed the CardioSEAL StarFlex, a newer model of that device. The StarFlex allows for the umbrella device to center itself to plug larger holes.

"This device is not only effective in children, but can also be used in teenagers and young adults," according to Douglas Moodie, M.D., M.S., chairman, Division of Pediatrics, Cleveland Clinic Children's Hospital in Cleveland, $\mathrm{OH}$, "Short term follow-up studies are very encouraging.

Such devices have "the potential to be as good as surgery without many of the risks inherent in open heart surgery," says Andrew Lashus, M,D., Cook Children's Medical Center. Fort Worth, TX, who is principal investigator on a phase III clinical trial of the CardioSEAL. StarFlex sanetioned by the Food and Drug Administration.

But some hospitals favor another device, the Amplatzer. Arno Zaritsky, chairman of the department of pediatrics at Children's Hospital of The King's Daughters Health System in Norfolk, VA, says, "Our pediatric cardiologists participate in trials using the Amplatzer atrial-septal defect, patent ductus ateriosus and ventricular septal defect devices, which have reduced the need for thoracic surgery, shortened the hospital stay and reduced cost. In our pediatric cardiologists' opinion, the Amplatzer, devices are superior to the StarFlex devices."

Farhouch Berdjis, M,D, pediatric cardiologist and medical director of the cardiac catheterization lab at Children's Hospital of Orange County in California, agrees. He says, "CHOC has had excellent results with the Amplaizer septal occluder," whereas the CardioSeal StarFlex has sustained breakage of the wires and device itself, caused injury to the heart and great vessels and left a residual hole. 


\section{Brief description}

Techniques that were begun in the 1980s were perfected in the 1990s so that hundreds of children each year who previously had to have surgery to correct their heart defects are now treated in the catherization laboratory.

Different types of occluder devices, which are currently in use are Amplatzer ASD occluder, Amplatzer muscular and perimembranous VSD occluder, Amplatzer duet occluder, vascular plugs, Giantureo Cook coil. Amplatzer devices are made of Nitinol and coils are made of stainless steel. Devices and coils do not interfare with use of microwave ovens or magnets and are not affected by metal detectors or MRI scans.

\section{PDA device closure}

In 1967, porstmann et al reported the use of ivalon plug to close PDA. Since then, several devices have been used including Raskind PDA occluder, Gianturco coils, carcdioseal, detachable coil for small PDA, umbrella device and Amplalzer PDA occluder, Usual practice nowadays is coil closure for small PDA less than $2.5 \mathrm{~mm}$ size and device closure mainly by amplatzer is for larger PDA more than $2.5 \mathrm{~mm}$ size.

\section{Device closure of ASD}

Percutaneous closure of secundum ASD is first described by King in 1976.From 1980s to 1990s there was virtual explosion of various devices like clamshell, Sideris buttoned, cardioSEAL and amplatzer device used to close ASD. Amplatzer device is slightly superior. With Proper case selection with adequate rim, the immediate success is almost $100 \%$.

\section{PFO device closure}

PFO is thought to be culprit in case of cryptogenic stroke and myocardial infarction due to emboli. The present recommendation is that in patient with history of cerebrovascular accidents, if after detail cardiae evaluation and cerebral blood flow studies, a cause and effect relationship is established, then device closure of PFO should be done with amplatzer PFO occluder.

* Sahid Gangalal National Heart Centre 


\section{Device closure of VSD:}

Device closure is an attractive atternalive to surgical closure for treatment of hemodynamically significant muscular defects. This is especially true in patient with associated complex congenital heart disease, multiple VSDs, complex muscular VSDs and postoperative residual VSDs and some post MI VSDs. Amplatzer devices are most commonly used device closure of VSD remains more challenging and technically demanding. Perimembrenous VSDs are even more demanding because of close proximity of aortic valvae, tricusdid valve and conduction tissue to the VSD.

\section{Device closure for other CHDs}

- Aorto-pulmonary (AP) window: There are some case repots of clostire of small AP windows with the device, Large device can interfare with aortic valve function. Distal AP window closure may associated with compression of right pulmonary artery.

- Rupture sinus of valsalva: There are few case report regarding this. Device can Interfere aortic vale function and chances of impingment over coronary origin will be there. Device deployment is safer in case of RSOV from noncoronary sinus.

- Aorto-pulmonary collaterals: Coil closure can be done postoperatively for such collaterals with significant lung supply.

- Venous collaterals: These are abnormal vessels that originated from systemic veins capecially after in patient after Glenn or Fontan operation, Coil or vascular plugs can be used if there is significant desaturation.

- Arterio- venous malformation: Ciol closure can be done in can of pulmonary AV fistula, cerebral AV malformation, and systemic AV fistula. 
- NEPALESE HEART JOURNAL •

\section{Conclusion:}

Device closure is an accepted modality for management of many congenital heart disease. Long term results of this technique are excellent and comparable to surgery. Amplatzer devices are more widely used nowadays. 